Guo, J.; Kerenyi, K.; Pagán-Ortiz, Jorge E.; Flora, E.; Afzal, B. Conditions (II): Theory

Verfügbar unter / Available at:

https://hdl.handle.net/20.500.11970/100215

Vorgeschlagene Zitierweise / Suggested citation:

Guo, J.; Kerenyi, K.; Pagán-Ortiz, Jorge E.; Flora, E.; Afzal, B. (2010): Submerged-Flow Bridge Scour under Maximum Clear-Water Conditions (II): Theory. In: Burns, Susan E.; Bhatia, Shobha K.; Avila, Catherine M. C.; Hunt, Beatrice E. (Hg.): Proceedings 5th International Conference on Scour and Erosion (ICSE-5), November 7-10, 2010, San Francisco, USA. Reston, Va.: American Society of Civil Engineers. S. 815-823. 


\title{
Submerged-Flow Bridge Scour under Maximum Clear-Water Conditions (II): Theory
}

\author{
J. Guo ${ }^{1}$, K. Kerenyi ${ }^{2}$, J. E. Pagan-Ortiz ${ }^{2}$, K. Flora ${ }^{3}$, and B. Afzal ${ }^{1}$
}

${ }^{1}$ Dept. of Civil Engineering, University of Nebraska-Lincoln, PKI 204D, 111067 th ST, Omaha, NE 68182; PH (402)-554-3873; email: jguo2@unl.edu ${ }^{2}$ Office of Infrastructure R\&D, Turner-Fairbank Highway Research Center, Federal Highway Administration, 6300 Georgetown Pike, McLean, VA 22101.

${ }^{3}$ Hydraulics Branch, Structure Maintenance and Investigation, California Dept. of Transportation, P.O. Box 942873, Sacramento, CA 94273-0001.

\section{ABSTRACT}

A theoretical model for the maximum scour depth under submerged bridge flow was proposed based on the mass and energy conservation laws as well as the recent flume experimental data. It is shown that the maximum scour depth can be described by a scour number and an inundation index. In general, for submerged flow the scour number increases with the inundation index, which is equivalent to the maximum scour depth increases with deck inundation level, decreases with increasing sediment size, and is independent of bridge girders. The proposed method is expected to be applicable to prototype flows without scaling effects since it was derived from the conservation laws. An application procedure was also suggested for bridge foundation design or field scour evaluation.

\section{INTRODUCTION}

In Guo et al. (2010), a series of flume data have been collected at the FHWA J. Sterling Jones Hydraulics Laboratory. The experimental conditions and the results are summarized in Tables 1 and 2, respectively, where $V_{u c}=$ approach velocity at upstream of bridge, $Q=$ experimental discharge, $R_{h}=$ hydraulic radius, $\mathrm{Re}=$ Reynolds number, $\mathrm{Fr}=$ Froude number, $d_{50}=$ median sediment size, $C_{g}=$ coefficient of gradation, $C_{u}=$ coefficient of uniformity, $h_{b}=$ bridge opening height based on the original bed, $y_{s}=$ maximum scour depth, $a=$ block depth of bridge deck, $I=$ inundation index, and $\left(h_{b}+y_{s}\right) /\left(h_{b}+a\right)=$ scour number. The experimental study showed that the horizontal scour range of a submerged flow depends on the width of bridge deck, and the design of a scour profile needs the maximum scour depth $y_{s}$, which cannot be reasonably estimated by the existing methods since the Arneson and Abt (1998) method predicted an adverse tendency with the test data, the Umbrell et al. (1998) method in general overestimated the present data, and the Lyn (2008) method underestimates most of the present data.

The purpose of this paper is to propose a theoretically based method for predicting the maximum scour depth under bridge-submerged flows. Specifically, a hypothesis based on the mass and energy conservation laws is first formulated, which is then tested with the collected data in Table 2 ; if the hypothesis is confirmed by the collected data, an application procedure is then presented for practical design. 
Table 1: Test conditions of approach flow, bridge deck and sediment

\begin{tabular}{lcc}
\hline \hline Approach flow & 3-girder deck & 6-girder deck \\
\hline$V_{u c}=0.41 \mathrm{~m} / \mathrm{s}$ & $d_{50}=1.14 \mathrm{~mm}$ & $d_{50}=1.14 \mathrm{~mm}$ \\
$Q=64.6 \mathrm{l} / \mathrm{s}$ & $C_{g}=1.45, C_{u}=1.77$ & $C_{g}=1.45, C_{u}=1.77$ \\
$R_{h}=13.9 \mathrm{~cm}$ & $h_{b}=(21.0,19.5$, & $h_{b}=(22.0,20.5$, \\
$\operatorname{Re}=5.7 \times 10^{4}$ & $18.0,16.5,15.0$, & $19.0,17.5,16.0$, \\
$\mathrm{Fr}=0.17$ & $13.5,12.0,10.5) \mathrm{cm}$ & $14.5,13.0,11.5) \mathrm{cm}$ \\
& & $d_{50}=2.18 \mathrm{~mm}$ \\
$Q=83.5 \mathrm{l} / \mathrm{s}$ & & $C_{g}=1.35, C_{u}=1.59$ \\
$R_{h}=13.9 \mathrm{~cm}$ & $h_{b}=(22.0,20.5,19.0$, \\
$V_{u c}=0.53 \mathrm{~m} / \mathrm{s}$ & & $17.5,16.0,14.5$, \\
$\operatorname{Re}=7.37 \times 10^{4}$ & & $13.0,11.5) \mathrm{cm}$ \\
Fr $=0.22$ & & \\
\hline \hline Note: $h_{u}=0.25 \mathrm{~m}, \mathrm{Fr}=V_{u c} / \sqrt{g} h_{u}, R e=R_{h} V_{u c} / \nu$ where $R_{h}=$ \\
$\quad$ hydraulic radius, and, $\nu=$ kinematic viscosity of water.
\end{tabular}

\section{HYPOTHESIS ON MAXIMUM SCOUR DEPTH}

Bridge flows are divided into three cases (Picek et al. 2007): (1) the upstream low chord of a bridge is partially submerged while the downstream low chord is unsubmerged, which is not discussed here; (2) both upstream and downstream low chords are partially submerged; and (3) a bridge is totally submerged. The last two cases are analyzed in this paper.

The problem is stated with Figure 1 where a bridge is over a steady river flow with clear water, the bridge deck is modeled with a rectangular box, $V_{u c}=$ critical velocity of approach flow at upstream of the bridge, $V_{u e}=$ effective velocity corresponding to the flow through the bridge, $h_{u}=$ depth of the flow at the upstream of the bridge before scour, $h_{b}=$ bridge opening height before scour, $a=$ effective thickness of deck blockage where the corresponding stagnation streamline divides the flow into two parts, $b=$ physical thickness of the deck blockage, $V_{b s}=$

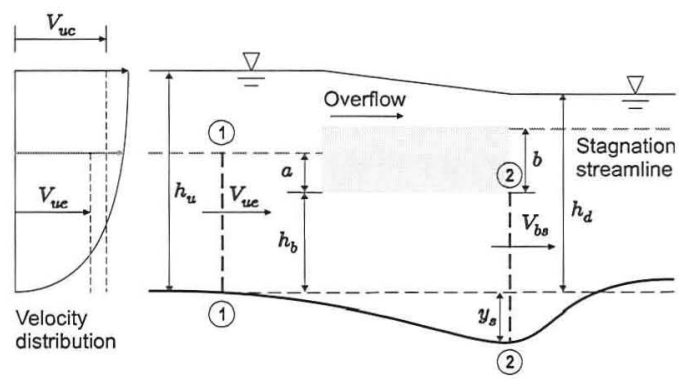

Figure 1: Sketch of definitions 
Table 2: Summary of test results of maximum scour depths

\begin{tabular}{|c|c|c|c|c|c|c|c|}
\hline $\begin{array}{l}\text { Bridge } \\
\text { opening }\end{array}$ & $\begin{array}{l}\text { Measure. } \\
\text { scour } \\
\text { depth }\end{array}$ & $\begin{array}{l}\text { Block } \\
\text { depth }\end{array}$ & $\begin{array}{l}\text { Run } \\
\text { time }\end{array}$ & $\begin{array}{c}\text { Inundate. } \\
\text { index }\end{array}$ & $\begin{array}{l}\text { Scour } \\
\text { number }\end{array}$ & $\begin{array}{l}\text { Calcul. } \\
\text { scour } \\
\text { depth }\end{array}$ & $\begin{array}{l}\text { Error } \\
(7)-(2)\end{array}$ \\
\hline$h_{b},(\mathrm{~cm})$ & $y_{s},(\mathrm{~cm})$ & $a,(\mathrm{~cm})$ & (hrs) & $I$ & $\frac{h_{b}+y_{s}}{h_{b}+a}$ & $y_{s},(\mathrm{~cm})$ & $(\mathrm{cm})$ \\
\hline$(1)$ & $(2)$ & $(3)$ & $(4)$ & $(5)$ & (6) & $(7)$ & $(8)$ \\
\hline \multicolumn{8}{|c|}{ 3-girder deck with $d_{50}=1.14 \mathrm{~mm}, C_{g}=1.45, C_{u}=1.77$} \\
\hline 21.0 & 2.77 & 4.00 & 36 & 1.53 & 0.95 & 2.76 & -0.01 \\
\hline 19.5 & 3.98 & 5.06 & 36 & 1.81 & 0.96 & 4.56 & 0.58 \\
\hline 18.0 & 5.18 & 5.06 & 48 & 2.10 & 1.01 & 5.29 & 0.11 \\
\hline 16.5 & 5.45 & 5.06 & 36 & 2.40 & 1.02 & 5.88 & 0.43 \\
\hline 15.0 & 6.35 & 5.06 & 36 & 2.90 & 1.06 & 6.35 & 0.00 \\
\hline 15.0 & 6.42 & 5.06 & 48 & 2.70 & 1.07 & 6.35 & -0.07 \\
\hline 13.5 & 6.41 & 5.06 & 48 & 3.01 & 1.07 & 6.74 & 0.33 \\
\hline 12.0 & 6.43 & 5.06 & 48 & 3.33 & 1.08 & 7.03 & 0.60 \\
\hline 10.5 & 7.31 & 5.06 & 48 & 3.69 & 1.14 & 7.26 & -0.05 \\
\hline 22.0 & 1.75 & 3.00 & 42 & 1.32 & 0.95 & 1.24 & -0.51 \\
\hline \multicolumn{8}{|c|}{ 6-girder deck with $d_{50}=1.14 \mathrm{~mm}, C_{g}=1.45, C_{u}=1.77$} \\
\hline 20.5 & 2.99 & 4.02 & 42 & 1.64 & 0.96 & 3.09 & 0.10 \\
\hline 20.5 & 2.98 & 4.02 & 42 & 1.64 & 0.96 & 3.09 & 0.11 \\
\hline 19.0 & 4.23 & 4.02 & 42 & 1.95 & 1.01 & 3.89 & -0.34 \\
\hline 19.0 & 4.52 & 4.02 & 42 & 1.95 & 1.02 & 3.89 & -0.63 \\
\hline 17.5 & 4.47 & 4.02 & 42 & 2.26 & 1.02 & 4.54 & 0.07 \\
\hline 16.0 & 5.55 & 4.02 & 42 & 2.56 & 1.08 & 5.07 & -0.48 \\
\hline 14.5 & 5.71 & 4.02 & 43 & 2.88 & 1.09 & 5.49 & -0.22 \\
\hline 13.0 & 5.93 & 4.02 & 48 & 3.21 & 1.11 & 5.82 & -0.11 \\
\hline 11.5 & 6.34 & 4.02 & 48 & 3.56 & 1.15 & 6.07 & -0.27 \\
\hline \multicolumn{8}{|c|}{ 6-girder deck with $d_{50}=2.18 \mathrm{~mm}, C_{q}=1.35, C_{u}=1.59$} \\
\hline 20.5 & 1.75 & 4.02 & 42 & 1.27 & 0.91 & 2.16 & 0.41 \\
\hline 19.0 & 2.83 & 4.02 & 42 & 1.51 & 0.95 & 2.84 & 0.00 \\
\hline 17.5 & 3.29 & 4.02 & 42 & 1.74 & 0.97 & 3.44 & 0.15 \\
\hline 16.0 & 4.14 & 4.02 & 42 & 1.98 & 1.01 & 3.97 & -0.17 \\
\hline 14.5 & 4.30 & 4.02 & 42 & 2.23 & 1.02 & 4.42 & 0.12 \\
\hline 13.0 & 4.62 & 4.02 & 42 & 2.48 & 1.04 & 4.79 & 0.18 \\
\hline 11.5 & 5.31 & 4.02 & 48 & 2.76 & 1.08 & 5.10 & -0.21 \\
\hline $7.0^{a}$ & 6.50 & 4.02 & 48 & 3.78 & 1.23 & 5.64 & -0.86 \\
\hline $2.5^{a}$ & 11.64 & 4.02 & 48 & 5.49 & 2.17 & 5.64 & -6.00 \\
\hline
\end{tabular}

${ }^{a}$ Excluded in Figures $6 \mathrm{c}, 8$ and 11 since the effect of the boundary layers cannot be neglected. 
average velocity at equilibrium maximum scour cross-section that is close to the outlet of the bridge flow according to the present experiments, and $h_{d}=$ depth of the tailwater before scour. Find the equilibrium submerged-flow scour depth, $y_{s}$, by considering a unit river flow.

To solve the problem, one can select a control volume consisting of crosssections 1-1 and 2-2, the upstream stagnation streamline, the left and low faces of the bridge deck, and the scoured river bed. Applying the energy conservation law to the control volume and neglecting the friction loss (due to the short distance), one can write

$$
h_{u}+\frac{\alpha_{1} V_{u e}^{2}}{2 g}=h_{d}+\frac{\alpha_{2} V_{b s}^{2}}{2 g}+K_{b} \frac{V_{b s}^{2}}{2 g}
$$

where $h_{u}=$ hydraulic head at cross-section 1-1 based on the original bed, $h_{d}=$ hydraulic head at cross-section 2-2, $\alpha_{1}$ and $\alpha_{2}$ are the energy correction factors, $g=$ gravitational acceleration, and $K_{b}=$ the bridge energy loss coefficient that is related to the difference of the upstream and downstream flow depths, $h_{u}-h_{d}$, the effective velocity, $V_{u e}$, and the gravitational acceleration, $g$. By dimensional analysis, one can assume

$$
K_{b}=\lambda_{0}\left(\frac{\sqrt{g\left(h_{u}-h_{d}\right)}}{V_{u e}}\right)^{m}
$$

where $\lambda_{0}$ and $m$ are two empirical parameters. Eq. (2) makes sure $K_{b}=0$ when $h_{u}=h_{d}$. On the other hand, applying the mass conservation law to the control volume gives

$$
\left(h_{b}+a\right) V_{u e}=\left(h_{b}+y_{s}\right) V_{b s}
$$

Solving for $h_{b}+y_{s}$ from Eqs. (1)-(3) gives

$$
\frac{h_{b}+y_{s}}{h_{b}+a}=\sqrt{\frac{\alpha_{2}+\lambda_{0}\left[\frac{\sqrt{g\left(h_{u}-h_{d}\right)}}{V_{u e}}\right]^{m}}{\alpha_{1}+2\left[\frac{\sqrt{g\left(h_{u}-h_{d}\right)}}{V_{u e}}\right]^{2}}}
$$

where the left-hand side is called a scour number. Unfortunately, the downstream flow depth $h_{d}$ is usually unknown. For an approximation, it is hypothesized

$$
h_{u}-h_{d}=\beta^{2}\left(h_{u}-h_{b}\right)\left(\frac{h_{b}+a}{h_{u}}\right)
$$

where $\beta$ is a fitting parameter. The factor of $\left(h_{u}-h_{b}\right)$ in Eq. (5) expresses an inundation level that, take a partially submerged flow for example, increases $h_{u}-h_{d}$ (since the energy loss increases with inundation) and makes $h_{u}-h_{d}=0$ at $h_{u}=h_{b}$. The fraction $\left(h_{b}+a\right) / h_{u}$ is introduced because $h_{u}-h_{d}$ should be independent of the upstream flow depth $h_{u}$ for significant inundation while it should be 1 for partially submerged flows. 
Referring to Figure 1 where the horizontal dashed line divides the approach flow into an overflow above the bridge and a pressure flow under the bridge, the unit flowrate, $q_{1}$, under the bridge in both cases can be estimated by

$$
q_{1}=h_{u} V_{u c}\left(\frac{h_{b}+a}{h_{u}}\right)^{n+1}
$$

where for approximately uniform flows of the present experiments $n=0$ and for fully developed turbulent flows $n=1 / 7$, and $a=$ effective thickness of deck blockage. Theoretically, the value of $a$ can be determined by a Bernoulli's equation in the dividing streamline if the fluid is ideal,

$$
a=b-\frac{V_{a}^{2}}{2 g}
$$

where $b=$ physical thickness of deck blockage, and $V_{a}=$ approach velocity in the dividing streamline. Practically, Eq. (7) gives a small value of $a$ because of the neglect of fluid viscosity. Nevertheless, for a thin deck with overhang shown in Figure 5 of Guo et al. (2010), the overhang forces the dividing streamline approximately at the elevation of the deck surface. Therefore, this study assumes

$$
a=b
$$

for totally submerged flow. Obviously, for partially submerged flow one has

$$
a=h_{u}-h_{b}
$$

For convenience, Eqs. (8) and (9) can be combined by

$$
a=\min \left(h_{u}-h_{b}, b\right)
$$

Considering Eq. (6), one has the effective velocity $V_{u e}$ for cross-section 1-1

$$
V_{u e}=\frac{q_{1}}{h_{b}+a}=V_{u c}\left(\frac{h_{b}+a}{h_{u}}\right)^{n}
$$

Substituting Eqs. (5) and (11) into the brackets of Eq. (4) gives

$$
\frac{\sqrt{g\left(h_{u}-h_{d}\right)}}{V_{u e}}=\beta \frac{\sqrt{g\left(h_{u}-h_{b}\right)}}{V_{u c}}\left(\frac{h_{u}}{h_{b}+a}\right)^{n-1 / 2}
$$

Defining an inundation index

$$
I=\frac{\sqrt{g\left(h_{u}-h_{b}\right)}}{V_{u c}}\left(\frac{h_{u}}{h_{b}+a}\right)^{n-1 / 2}
$$

and substituting Eq. (12) into Eq. (4) gives

$$
\frac{h_{b}+y_{s}}{h_{b}+a}=\sqrt{\frac{1+\lambda_{1} I^{m}}{1+\lambda_{2} I^{2}}}
$$




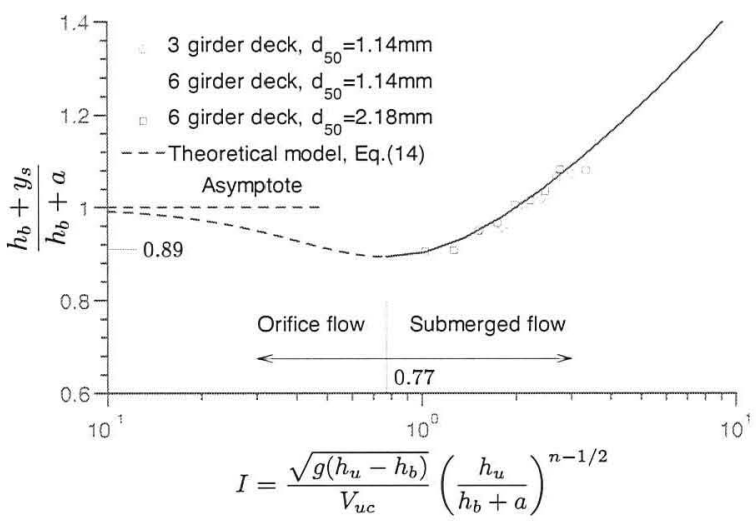

Figure 2: Test of hypothesis on maximum scour depth

which is the hypothesis of the maximum scour depth, where the energy correction factors $\alpha_{1}$ and $\alpha_{2}$ have been taken to be 1 , the deviation due to this assumption can be combined to the model parameters $\lambda_{1}\left(=\lambda_{0} \beta^{m}\right), \lambda_{2}\left(=\lambda_{0} \beta^{2}\right)$ and $m$, which are determined in next section.

\section{TEST OF HYPOTHESIS}

Columns 5 and 6 in Table 2 tabulate the values of the inundation index $I$ and the scour number $\left(h_{b}+y_{s}\right) /\left(h_{b}+a\right)$, respectively, for the experimental data. To test Eq. (14), columns 5 and 6 are plotted in Figure 2 where the data from different sediment sizes, different girder numbers and different inundation levels almost collapse into a single curve. This means the two similarity numbers reasonably describe the submerged flow scour. Furthermore, a least-squares fitting process with MatLab gives the model parameters

$$
\lambda_{1}=1.71, \lambda_{2}=2.33 \text {, and } m=2.45
$$

which fit Eq. (14) to the present experimental data with a correlation coefficient $R^{2}=0.976$ and a standard deviation $\sigma_{2}=0.015$. This means with a $95 \%$ confidence interval, the estimated scour depth from Eq. (14) has an error of $\pm 3 \%\left(h_{b}+a\right)$.

Note that Figure 2 has a minimum value at $I=0.77$ and $\left(h_{b}+y_{s}\right) /\left(h_{b}+a\right)$ $=0.89$, which is the criterion between unsubmerged and submerged flows. At this minimum, the scour depth is $y_{s}=0$ and the flow is partially submerged where $a=h_{u}-h_{b}$, which leads to

$$
h_{b} / h_{u}=0.89 \text { or } h_{u} / h_{b}=1.1
$$

This implies that submerged flow scour occurs under the conditions

$$
I=\frac{\sqrt{g\left(h_{u}-h_{b}\right)}}{V_{u c}} \geq 0.77 \text { and } h_{u} / h_{b} \geq 1.1
$$


The latter condition is similar to that of submerged culvert flow where $h_{u} / h_{b} \geq$ 1.2 (Gupta 2008, p779). The dashed line in Figure 2 is just an extension of Eq. (14), which does not have any practical meaning since it corresponds to an orifice flow where the downstream edge of a bridge is unsubmerged. Nevertheless, it helps examine the functional structure of Eq. (14). Mathematically, when $h_{u}$ approaches to $h_{b}$, or the inundation index $I$ approaches to zero, the scour number has an asymptote $\left(h_{b}+y_{s}\right) /\left(h_{b}+a\right) \rightarrow 1$, which is true since $a=h_{u}-h_{b} \rightarrow 0$ and $y_{s}=0$. This asymptote shows that the structure of Eq. (14) is physically reasonable. In brief, for submerged flow the scour number increases with the inundation index.

The effect of sediment size is through the upstream critical velocity $V_{u c}$. When sediment size increases, the upstream critical velocity $V_{u c}$ increases, which decreases the inundation index $I$ and then reduces the scour number $\left(h_{b}+y_{s}\right) /\left(h_{b}+\right.$ a). In other words, scour depth decreases with increasing sediment size.

The present analysis has approximated the approach velocity distribution to be uniform, which implies the effects of the bottom and side wall boundary layers can be neglected when estimating the flowrate through a bridge. Furthermore, the deck elevation must be much higher than the bottom boundary layer. Otherwise, the estimated flowrate through a bridge is much larger than the real flowrate, which results in a large effective velocity $V_{u e}$ in Eq. (4) or a small inundation index in Eq. (13) and, as a result, a very small scour number or depth. This explains why the last two tests in Table 2 are excluded in analyses and why the predictions of the proposed method are much smaller than the measurements where the inundation ratio $h_{u} / h_{b}=3.57$ and 10 , respectively. In practice there are seldom submerged flows with an inundation ratio $h_{u} / h_{b}>2$. For prototype flows with fully developed turbulent boundary layers, it is suggested to use $n=1 / 7$ in Eq. (6) for estimating the flowrate through a bridge and Eq. (13) for inundation index.

In briefly, the proposed theoretical model, Eq. (14), has been confirmed with the present experimental data under threshold conditions, and the model parameters are defined by Eq. (15).

\section{APPLICATION PROCEDURE}

Unlike a pure empirical method that is restricted to the range of calibrated data, the proposed method is expected to be applicable to similar prototype bridge flow without scaling effects because it is mainly derived from the mass and energy conservation laws. These laws are true within considered framework whatever are inputs, outputs or system modifications. To apply the proposed method, the following procedures are suggested.

Step 1: From the approach flow depth, $h_{u}$, and bed materials size, $d_{50}$, calculate the critical velocity, $V_{u c}$, from Eq. (2) in Guo et al. (2010).

Step 2: Check if the scour is clear water scour. If the upstream velocity, $V_{u}$, is less than or equal to the critical velocity, $V_{u c}$, the proposed method is used.

Step 3: Calculate the effective thickness of deck blockage, $a$, from Eq. (10).

Step 4: Calculate the inundation index, $I$, from Eq. (13) where $n=1 / 7$ is 
used for fully developed turbulent boundary layers.

Step 5: Check if the flow is submerged flow according to Eq. (17).

Step 6: If yes, calculate the scour number from Eq. (14), and solve for scour depth, $y_{s}$.

Step 7: Plot the design scour profile according to Eqs. (6) and (8) in Guo et al. (2010).

Column 7 in Table 2 was obtained using the above procedures, and column 8 shows the absolute errors of predictions. It is seen that except for the last two tests, all errors are less than or equal to $6.3 \mathrm{~mm}$ that is usually within the uncertainties of flume measurements. The large errors of the last two tests originate from the amplified upstream effective velocities in the calculations, by neglecting the effect of boundary layers. The real effective velocities were significantly smaller since the deck elevations were close to the bottom boundary layers. Without the last two tests, the correlation coefficient between the predictions and the measurements is $R^{2}=0.929$.

\section{CONCLUSIONS}

The theoretical model, Eq. (14), for the maximum scour depth has been confirmed by the experimental data in Guo et al. (2010), which shows that the maximum scour depth can be described by the scour number and the inundation index. In general, for submerged flow the scour number increases with inundation index, which is equivalent to the maximum scour depth increases with deck inundation level, decreases with increasing sediment size, and is independent of bridge girders. The proposed method is expected to be applicable to prototype flows without scaling effects, and an application procedure has been suggested for bridge foundation design or field scour evaluation.

\section{ACKNOWLEDGMENTS}

This study was financially supported by the FHWA Hydraulics R\&D Program with Contract No. DTFH61-04-C-00037. The writers would like to thank Mr. Oscar Berrios for running the tests and preparing some of the figures. The writers are also thankful to Mr. Bart Bergendahl at FHWA for his constructive comments and suggestions.

\section{REFERENCES}

Arneson, L. A., and Abt, S. R. (1998). "Vertical contraction scour at bridges with water flowing under pressure conditions." Transportation Research Record. $1647,10-17$.

Guo, J., Kerenyi, K., Flora, K., and Afzal, B. (2010). "Submerged-flow bridge scour under maximum clear-water conditions (I): Experiment." 5th International Conference on Scour and Erosion, San Francisco, CA.

Gupta, R. S. (2008). Hydrology and Hydraulic Systems. 3rd ed., Waveland Press. 
Lyn, D. A. (2008). "Pressure-flow scour: a re-examination of the HEC-18 equation." J. Hydraul. Engrg., 134(7), 1015-1020.

Picek, T., Havlik, A., Mattas, D., and Mares, K. (2007). "Hydraulic calculation of bridges at high water stages." J. Hydraul. Res., 45(3), 400-406.

Richardson, E. V., and Davis, S. R. (2001). Evaluation Scour at Bridges. HEC18, FHWA-NH-01-001, 4th Ed., U.S. Dept. of Transp., Washing, D.C.

Umbrell, E. R., Young, G. K., Stein, S. M., and Jones, J. S. (1998). "Clearwater contraction scour under bridges in pressure flow." J. Hydraul. Engrg., 124(2), 236-240. 